\title{
Experimental investigation of convective heat transfer using ethylene glycol-based nano-fluid
}

\author{
Muhammad Shoaib Rafiq ${ }^{1, *}$, Hafiz Muhammad $\mathrm{Ali}^{2}$, and Amir Sultan ${ }^{3}$ \\ ${ }^{1}$ Mechanical Engineering Department, University of Engineering and technology (UET), Taxila 47050, Pakistan \\ ${ }^{2}$ Mechanical Engineering Department, King Fahad University of Petroleum and Minerals (KFUPM), Dhahran 31261, Saudi Arabia \\ ${ }^{3}$ Mechanical Engineering Department, University of Engineering and technology (UET), Taxila 47050, Pakistan
}

\begin{abstract}
Coolant plays important characteristic in automobile industry to prevent failure and damage by balancing the temperature. Due to this approach, coolants are being used as new thermal fluid to study the heat transfer coefficient performance. This study consists of an experimental investigation of internal convective heat transfer of 50:50 Water-Ethylene Glycol based Nano-fluid through a copper tube of $18 \mathrm{~mm}$ external diameter and $16.5 \mathrm{~mm}$ internal diameter and a test section of $1 \mathrm{~m}$ in a fully turbulent regime. Total convective heat transfer coefficient of Nano fluid at three different volumetric concentrations of nanoparticles is estimated. Local convective heat transfer at eight different points along the tube at varying Reynolds number is also determined. At $0.15 \%$ volumetric concentration of $\mathrm{SiO}_{2}$ Nanoparticles (NPS) $29 \%$ increment in convective heat transfer coefficient (CHT) is observed. The decrease in the heat transfer rate is observed with changing distance axially. Particles disorganized movement of NPs and undulation in the fluid and increased in thermal conductivity of Nano fluid can be possible reason for extra ordinary change in heat transfer.
\end{abstract}

Keywords: Turbulent flow, $\mathrm{SiO}_{2}$ nanoparticles, local convective heat transfer, Ethylene Glycol, Nano fluids, heat transfer

\section{Introduction}

Liquid stream and heat transfer (HT) in a channel has been a famous region of specialists because of its generally application, for example, electronic devices and heat exchangers (HX) [1,2]. HT is one of the most significant in engineering sciences; its applications become significant concerning the subject of energy utilization streamlining in different modern procedures. For quite a long time, endeavours have been done to upgrade the HT rate, lessen HT time, limit size of heat exchangers, lastly increase energy and fuel efficiencies [3]. Jafari et al. [4] numerically considered stream and HT in a creased channel with throbbing speed profile. Different researchers have worked on tubes to improve them to obtain higher efficiency by applying different enhancement techniques. Heat enhancement of fluid can be improved by modification of tubes material. Increased turbulence, boundary layer disturbance and increased HT surface area are main input factors involved in increasing HT.

Coming towards the nanoparticles, Nano-meter size particles were first discovered by Granqvist et al. [5] and after that the particles were called as nanoparticles. Choi [6] and his team was first one using nanoparticles(NPs) suspension for preparation of NF to determine them as best heat transferring source rather than other conventional fluids. Maxwell [7] is first one in history of NFS who did numerous theoretical research on TC of NPs suspension and after that research on Nano fluid was done by many researchers in past 100 years. With increase in demand w.r.t time, high-performance HT fluids are prepared. Nanofluids (NFs) are considered to offer important advantages over conventional heat transfer fluids. Choi et al.[8]was first one who observed $160 \%$ enhancement in TC of engine oil by using suspension of $1.0 \%$ volume carbon nanotubes. Ali et al. [9] also used Cu-water NFs to investigate effect of Brownian motion on natural convection stream and HT in a notched walled in area loaded up with NFS numerically. Vermahmoudi et al. [3] find out the general heat transfer coefficient (HTC) and heat transfer (HT) of water based $\mathrm{Fe}_{2} \mathrm{O}_{3}(0.15,0.14$ and $0.65 \%$ vol.) NFs in a smaller air cooled HX under laminar stream conditions. Greatest improvements of the general HTC and HT rate contrasted with base fluid were separately equivalent to $13 \%$ and $11.5 \%$ at $0.65 \%$ vol. $\mathrm{Fe}_{2} \mathrm{O}_{3}$-water Nanofluid was also used by Ravi Kumar et al. [10] to find out the Nusselt number $(\mathrm{Nu})$ at different volume concentrations $0.005 \%, 0.01 \%$, $0.03 \%$ and $0.06 \%$ of the NPs with Reynolds number range from 15,000 to 30,000. Highest Nu increment was almost $14.7 \%$ in case of $0.06 \%$ vol. concentration inside inner tube of HX. Umar Khan et al. [11] explained the HT

* Corresponding author: m.shoaibrafiq@students.uettaxila.edu.pk 
investigation and flow of NFs between the parallel plates by using three different shapes of Copper $(\mathrm{Cu})$ nanoparticles (NPs) for preparation of $\mathrm{Cu}$-water Nanofluid. They concluded that HT rate is also affected because of shape factors.

Lee et al. [12] prepared aqueous NFs using two-step method by adding $\mathrm{Al}_{2} \mathrm{O}_{3}$ in low volume concentrations 0.01-0.03 vol.\% with Distilled water (DI) as based fluid. They came to find out that TC increases linearly with concentration. While viscosity decreases with increase in temperature. Hwang et al. [13] and Eastman et al. [14] also studied about TC increase of base fluid by adding NPs. Sir Ali et al. [15] studied about possible methods for enhancement of HT for Nanofluids that could be reduction in thermal boundary layer or Brownian motion of NPs. Peyghambarzadeh et al. [16] determined that TC of water/EG based fluids by adding $\mathrm{Al}_{2} \mathrm{O}_{3} \mathrm{NPs}$. They did experimentation to study $\mathrm{HT}$ enhancement of car radiator and resulted that TC increases up to $40 \%$. Sir Ali et al. [17] used ZnO NPs in different concentrations of $0.01 \%, 0.08 \%, 0.2 \%$ and $0.3 \%$ Vol. in water as base fluid to find out the enhancement of HT of car radiator. They determined that HT rate increases $6.4-7 \%$ at 0.01 vol. $\%$ due to low concentration and increases to $46.5 \%$ for $0.2 \%$ that is significant enhancement in HT. Leong et al. [18] performed experiments to study thermal performance of car radiator using $\mathrm{Cu} / \mathrm{EG}$ Nanofluid by changing volume concentrations. They came to find that enhancement in HT was about $3.8 \%$ because of $\mathrm{Cu}$ particles concentrations of $2 \%$ in base fluid.

Wadd et al. [19] performed experiments to determine the comparison between metal $(\mathrm{Cu}) /$ water and non-metal $\left(\mathrm{TiO}_{2}\right) /$ water NFs. They found out the results that $\mathrm{TiO}_{2}$-based $\mathrm{NF}$ showed less $\mathrm{TC}$ than $\mathrm{Cu}$-based Nanofluid because $\mathrm{Cu}$ NPs have more TC than $\mathrm{TiO}_{2}$ NPs. Kole and Dey [20] determined the TC enhancement using EG based Nanofluid and $\mathrm{ZnO}$ nanoparticles (NPs) in volume concentrations of $3.75 \%$. They found that TC increases $40 \%$ as compared to base fluid EG. Zakaria et al. [21] prepared NFs utilizing EG-water mixture as base fluid and $\mathrm{Al}_{2} \mathrm{O}_{3} \mathrm{NPs}$ ranging from 0.1,0.3 and $0.5 \%$ volume concentration. They discovered that $\mathrm{TC}$ increases as a function of volume concentration. Thermal conductivities for $0.5 \%$ volume concentration of $\mathrm{Al}_{2} \mathrm{O}_{3}$ were $0.6478 \mathrm{~W} / \mathrm{mK}$ and $0.2816 \mathrm{~W} / \mathrm{mK}$ for 0 and $100 \% \mathrm{EG}$ content in water.

Sundar et al.[22] Likewise tentatively estimated the TC of EG and water blend based $\mathrm{Al}_{2} \mathrm{O}_{3}$ and $\mathrm{CuO}$ NFs at various volume concentrations and temperatures. They found that the TC upgrade of the $\mathrm{Al}_{2} \mathrm{O}_{3}$ Nanofluid differs from $9.8 \%$ to $17.89 \%$ and for $\mathrm{CuO} \mathrm{NF}$ it shifts from $15.6 \%$ to $24.56 \%$ inside the temperature scope of $15{ }^{\circ} \mathrm{C}$ to $50{ }^{\circ} \mathrm{C}$ at $0.8 \%$ volume concentration (for example contrasted and that of the base liquid separately). Reddy and Rao [23] explored $\mathrm{TiO}_{2} \mathrm{NFs}$ with EG-water as base liquid at various volume concentration and at various temperatures. The TC upgrade for waterEG (60/40) based $\mathrm{TiO}_{2} \mathrm{NFs}$ was estimated to be $1.94 \%$ and $4.38 \%$ individually contrasted and that of the base liquid, when the concentration expanded from $0.2 \mathrm{vol} \%$ to $1.0 \mathrm{vol} \%$. Sohaib Usman et al. [24] examined the convective HT of alumina-water Nanofluid using $0.3,0.5$ and $1 \%$ volume concentration at Re between 200-7000. They did all this in rectangular channel consistently heated in laminar, turbulent and transition flow streams. 54\% enhancement with $1 \%$ NF was obtained in case of laminar flow while $11 \%$ was attained in turbulent flow regime. Pak and Cho [25] tentatively estimated the HT and rubbing coefficients of $\mathrm{Al}_{2} \mathrm{O}_{3}$-water and $\mathrm{TiO}_{2}$-water $\mathrm{NFs}$ for a completely created turbulent stream. The expansion of the $\mathrm{Al}_{2} \mathrm{O}_{3}$ nanoparticles brought about a $45 \%$ upgrade in the $\mathrm{HTC}$ at a volume grouping of $1.3 \%$, with a $75 \%$ improvement at a centralization of $2.7 \%$. Wen and Deng [26] researched the HT expansion given by $\mathrm{Al}_{2} \mathrm{O}_{3}$-deionised water NFs in the laminar stream area, considering volume convergences of $0.6,1$, and $1.6 \%$. The neighbourhood HTC results for the three NFs indicated improvements in the HT contrasted and that for water. The upgrade was critical in the passageway locale, with an estimation of $45 \%$, and diminished towards the exit of the test area to $14 \%$. It was recommended that this HT improvement was the after effect of molecule developments and the decrease of the limit layer thickness.

Nassan et al. [27] performed comparison of experimental $\mathrm{HT}$ attributes for $\mathrm{CuO} /$ water and $\mathrm{Al}_{2} \mathrm{O}_{3}$ /water $\mathrm{NFs}$ in $1000 \mathrm{~mm}$ length of square cross-section duct under laminar flow and consistent HTC. The outcomes demonstrate that an extensive improvement of convective has been done; nonetheless, $\mathrm{CuO}$ /water Nanofluid communicates more upgrades in convective HTC contrasted with $\mathrm{Al}_{2} \mathrm{O}_{3} /$ water Nanofluid at similar volumetric concentrations. Nguyen et al. [28] tentatively research the impact using $\mathrm{Al}_{2} \mathrm{O}_{3}$-water NFs with $47 \mathrm{~nm}$ NPs . Experimental information, acquired for turbulent flow system, has plainly demonstrated that the incorporation of NPs into refined water has created an impressive improvement of the cooling square convective HTC.

\section{Experimental setup and Nano-fluid preparation 2.1 Experimental setup}

An illustrative outline of exploratory arrangement that is utilized in the examination is appeared in figure 1 . This exploratory loop is made for examine the inward CHT in completely created turbulent stream regime. The circle was comprised of a $1000 \mathrm{~mm}$ long test area of copper tube with passage length of $165 \mathrm{~mm}$, and liquid is pumped by using a PEDROLLO pump that have capacity of flow up to $40 \mathrm{~L} / \mathrm{min}$. The volumetric stream rate is estimated by utilizing board type glass fluid flow meter that can deliver up to $20 \mathrm{~L} / \mathrm{min}$. The flow meter alignment was done physically. 
The stream meter was installed directly after the discharge of the pump. Test segment was comprised of level cylinder with inward dia of $16.5 \mathrm{~mm}$ and external dia of $18.5 \mathrm{~mm}$ and a consistent thermal flux of most extreme 450 watt was applied. Glass fleece was utilized for the protection of the test segment to keep away from any heat misfortune. A rope heater (EGR-100, omega) is used to heat the test area supplying greatest intensity of 500 watt that was appended to a DC supply (6575A, Agilent, USA) that can supply most extreme voltage of 120V. Eight K-type thermocouples were used to mount $1 \mathrm{~mm}$ inside the test tube to acquire divider temperatures, these thermocouples were soldered at a distance of 25.4mm (P1), 152.4mm (P2), 292.1mm (P3), 318mm (P4), 431.8mm (P5), 571.5mm (P6), 723.9mm (P7), 990mm (P8).

Two K-type thermo-couples for comparison, one at inlet and one at outlet to get the mass temperature of the NF are additionally appended. These thermo-couples are connected with a data logger. Information is examined after every 5 sec by utilizing Agilent (Agilent, 34972A, USA) information analyser. When it was finished across the test area, NF was cooled utilizing the radiator that was put toward the finish of the test segment. The liquid again comes into the supply and circle proceeds. The Distilled water (DI) was utilized to approve the exploratory loop for underlying tests.

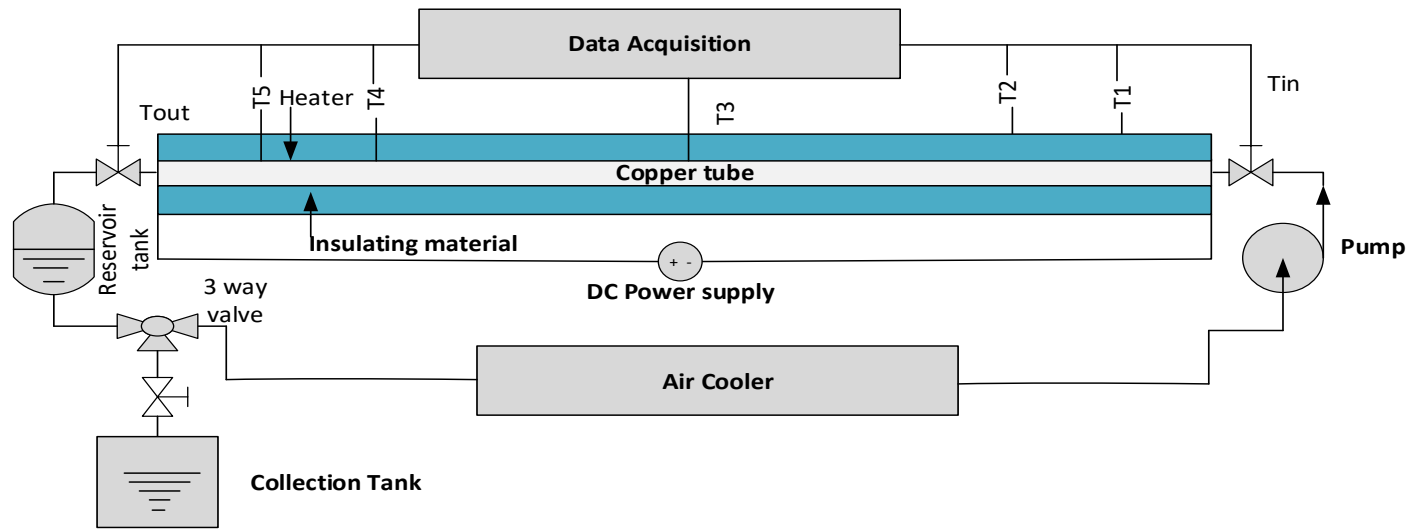

Figure 1. Schematic outline of the exploratory arrangement Figure 1 demonstrates the exploratory arrangement with all the joined parts. Letter sets $(\mathrm{H}, \mathrm{I}, \mathrm{J}, \mathrm{K}, \mathrm{L}, \mathrm{M})$ speak to the name of parts DC power supply, data logger, laptop and rope heater respectively.

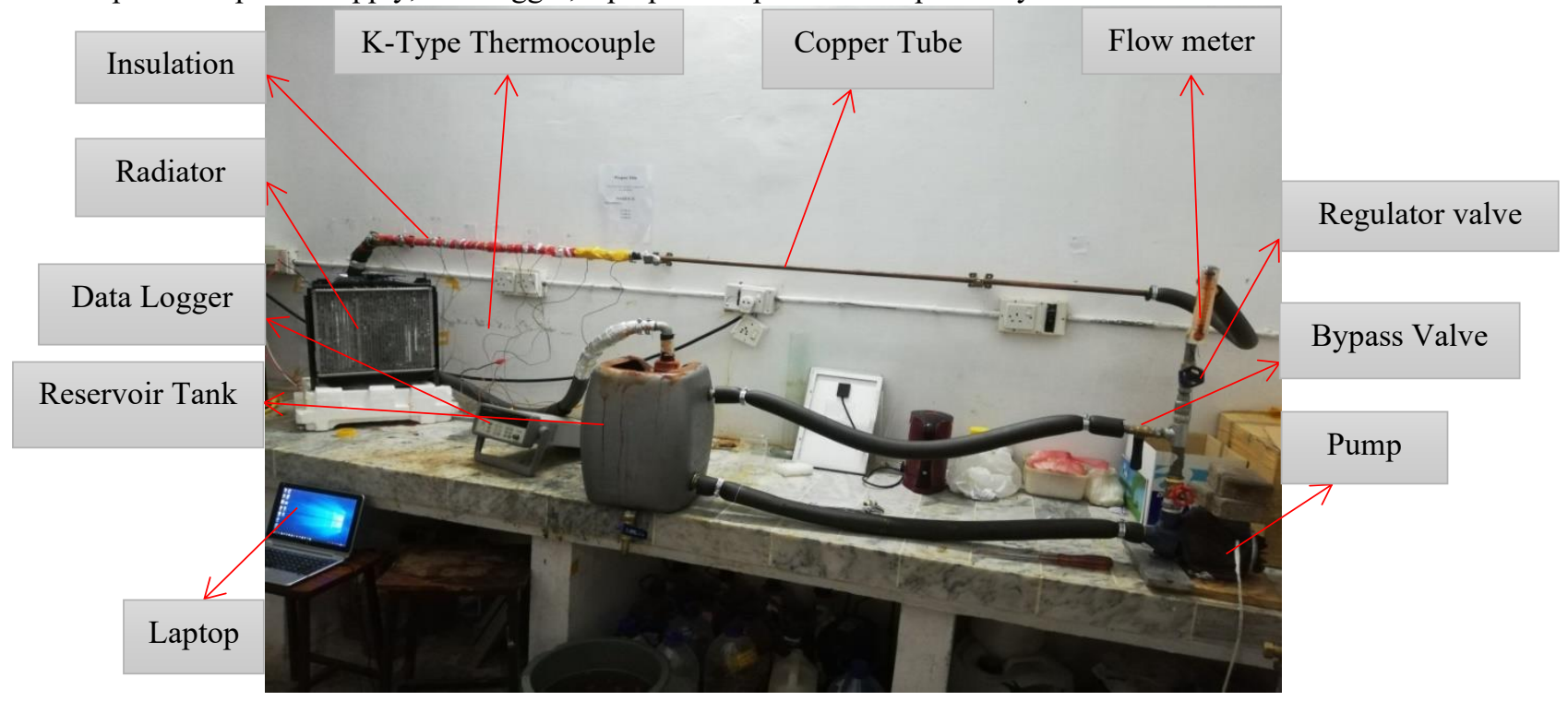

Figure 2 Experimental Setup (1) 


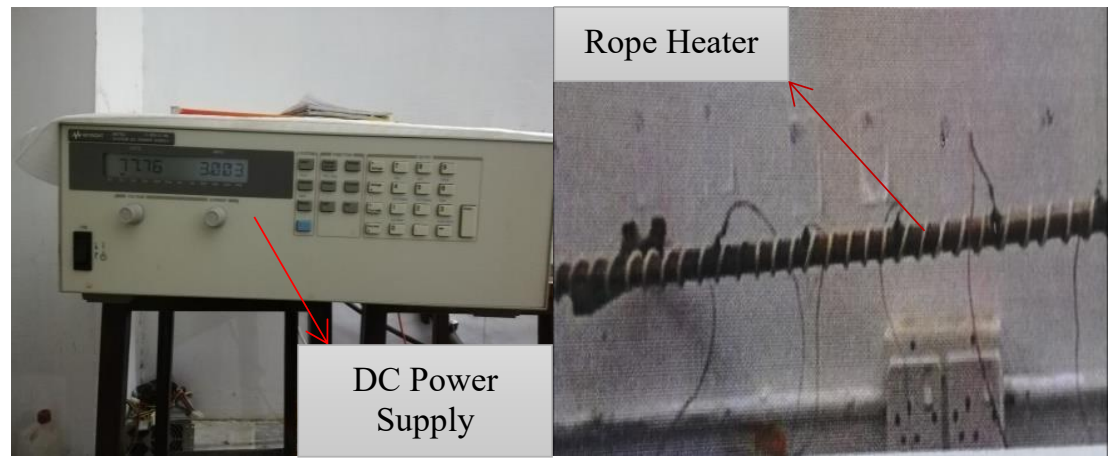

Figure 3. Experimental Setup (2)

\subsection{Nanofluids (NFs) Preparation}

$\mathrm{SiO}_{2}$ Nanoparticles (NPs) alongside water and Ethylene Glycol (EG) as base liquid were utilized in this research. NPs were prepared and provided by nanostructured and Amorphous materials Inc. Round SiO2 NPs (Size-20nm) with volume convergence of $0.05 \%, 0.10 \%$ and $0.15 \%$ is blended with De-ionized (DI) water and Ethylene Glycol (50:50). Basic examination was completed to affirm the weight level of the particles and component as referenced by business organization. To ensure that there were no settlements of NPs in the test circle, the distinction in the NPs conc. was observed at start and end of the experiment. The experimental test was also completed with DI water to ensure that the circle formation was not influenced by the remnants of NP trapped in the loop.

Table 1 Properties of $\mathrm{SiO}_{2} \mathrm{NPs}$

\begin{tabular}{cccccc}
\hline Purity & Size & Morphology & Specific heat & $\begin{array}{c}\text { Thermal Conductivity } \\
\text { (TC) }\end{array}$ & Density $(\boldsymbol{\rho})$ \\
\hline $99 \%$ & $20 \mathrm{~nm}$ & Spherical & $745 \mathrm{j} / \mathrm{Kg} \mathrm{K}$ & $1.4 \mathrm{~W} / \mathrm{m} \mathrm{K}$ & $5240 \mathrm{Kg} / \mathrm{m}^{3}$ \\
\hline
\end{tabular}

A Two-step approach was utilized to set up the utilized NFs. A complete $1100 \mathrm{ml}$ NF solution was prepared and to ensure the stability of the NPs the ultra-sonication of the arrangement was accomplished for six hours. The mixture of solution was combined before the ultra-sonication by utilizing homogenizer made by IKA at $6500-7500 \mathrm{rpm}$ for 6-7 minutes. The prepared solution stays stable for one week after testing. Sodium dodecyl benzene sulphonate (SDBS) was utilized as a surfactant to alter the $\mathrm{pH}$ and increment the stability of the NFs.

\subsection{Thermophysical properties of Nano fluids (NFs)}

Eq. (1) is used to calculate the volume fraction (Ø) of Nano fluid

$$
\emptyset=\frac{m_{p} / \rho_{p}}{m_{p} / \rho_{p}+m_{b f} / \rho_{b f}}
$$

The accompanying relationship has been utilized to anticipate NFs thickness at various temperatures and concentrations.

$$
\rho_{n f}=\rho_{n p} \emptyset+\rho_{b f}(1-\emptyset)
$$

Where $\rho_{\mathrm{nf}}, \rho_{\mathrm{bf}}$ and $\rho_{\mathrm{np}}$ are density of Nanofluid, base-fluid and nanoparticles respectively. Here $\varnothing$ is volume concentration of NPs, where specific heat of NF can be calculated by energy balance equation.

$$
\begin{gathered}
C_{n f}=\frac{\rho_{n p} C_{n p} \emptyset+\rho_{b f} C_{b f}(1-\emptyset)}{\rho_{n f}} \\
\frac{\mu_{n f}}{\mu_{b f}}=(1+\emptyset)^{11.3}\left(1+\frac{T_{n f}}{70}\right)^{-0.038}\left(1+\frac{d_{n p}}{170}\right)^{-0.061}
\end{gathered}
$$


Here $\mu_{\mathrm{nf}}, \mu_{\mathrm{bf}}, \mathrm{T}_{\mathrm{nf}}$ and $\mathrm{d}_{\mathrm{np}}$ are viscosity of nanofluid, base fluid and temperature of Nanofluid. These equations are obtained by the bend fittings between temperatures $0-120^{\circ} \mathrm{C}$ [29]. The heat transfer co-efficient was obtained by using following equation.

$$
\begin{gathered}
h=\frac{q}{T_{w i}-T_{b}} \\
Q=\dot{m} C_{p}\left(T_{\text {out }}-T_{\text {in }}\right)
\end{gathered}
$$

Where heat flux of the tube wall is $\mathrm{q}$, inner wall temperature of the tube is $\mathrm{T}_{w i}$ and bulk temperature is $\mathrm{T}_{\mathrm{b}}$ determined by using the Avg. of inlet and outlet temperatures. Thermo-physical properties of NFs depend upon temperature and used in the determination of HTC.

\section{Results and Discussion:}

\subsection{Validation of Experimental Setup}

The experimental setup is validated with Dittus-Boelter theoretical correlation as given by eq. (7) using copper tube with distilled water as working fluid in Re ranging from 5000-26000.Experimental data show good agreement with theoretical model within $\pm 7 \%$ deviation.

$$
N u(D B)=0.0236\left(R e^{0.8}\right)\left(P r^{0.3}\right)
$$

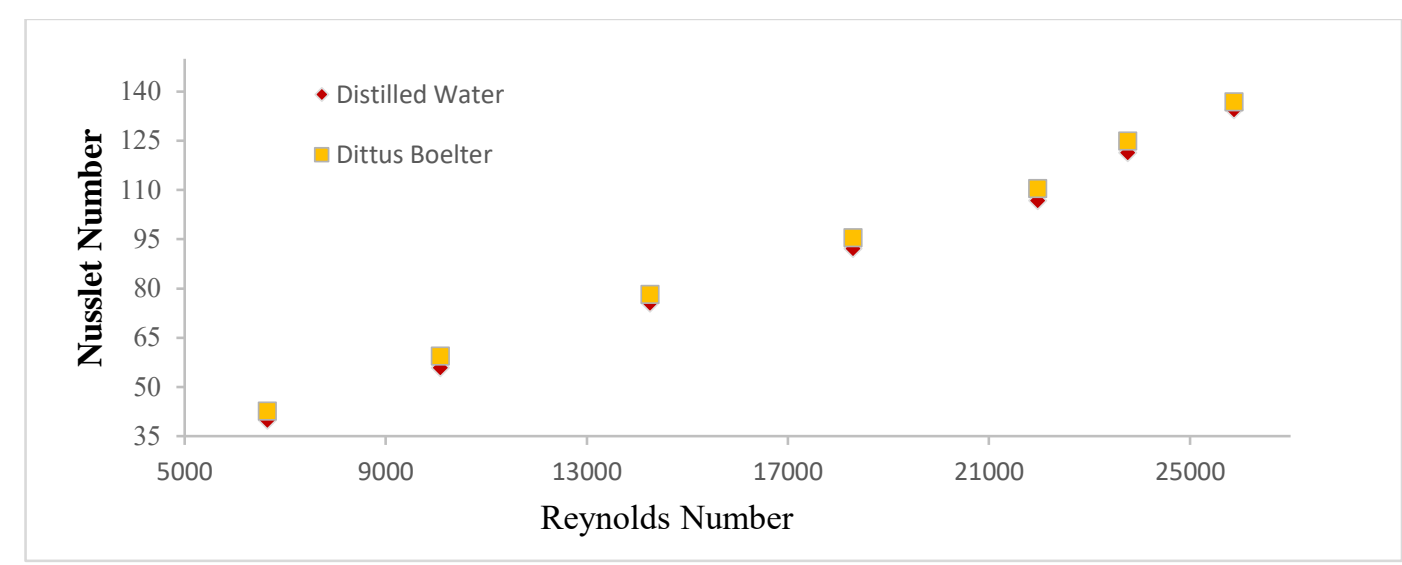

Figure 4. Validation of experimental setup

\subsection{Total Convective Heat Transfer}

Convective heat transfer (CHT) co-efficient is used to calculate the HT during convection, fluid flow or change in phase between a fluid and the solid. Increase in the variation of total CHT co-efficient and local convective CHT at various points in a tube is observed with increase in RE number and conc. of SiO2 NPs. With increase in power it was more than the base fluid. 


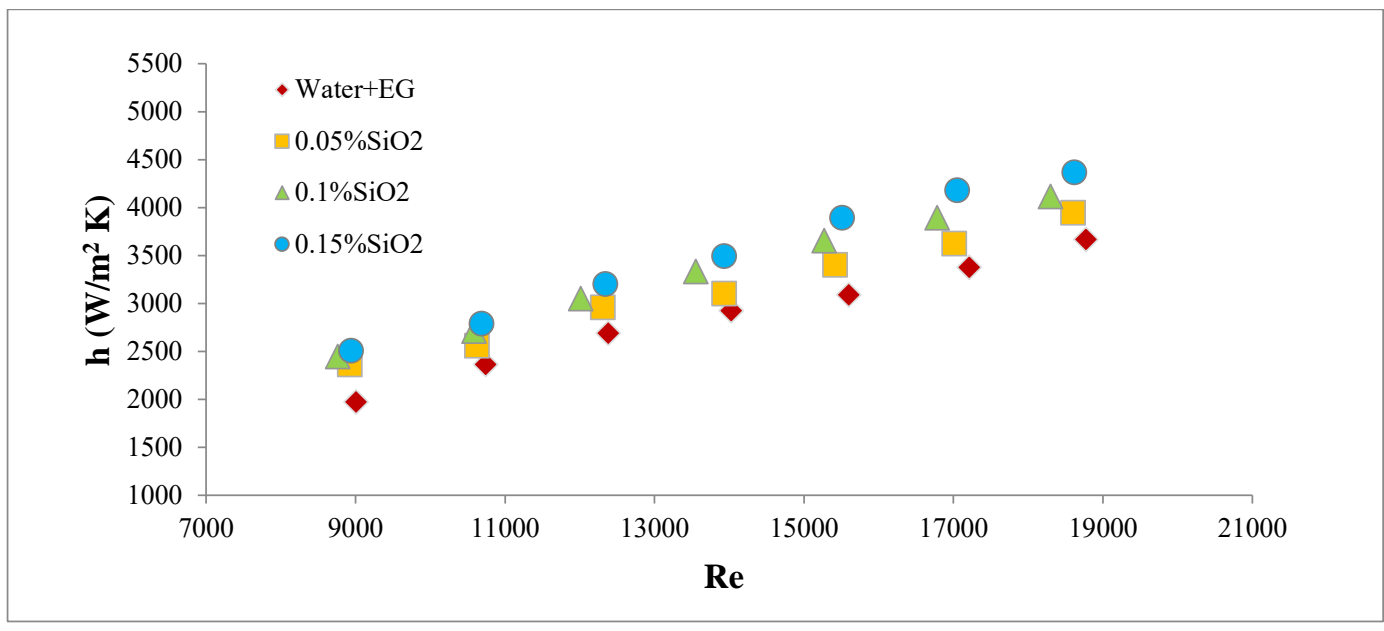

Figure 5. Reynolds number vs Convective heat transfer coefficient

The flow regime was fully turbulent that's why higher CHT is detected. The heat transfer rate is higher at $0.15 \% \mathrm{SiO}_{2}$ concentration at higher Reynolds number. In case of $0.05 \% \mathrm{SiO}_{2} \mathrm{NPs}, 13 \%$ increase in CHT is observed. For $0.10 \%$ and $0.15 \%$ average increase is $18 \%$ and $20 \%$. It has been resulted that avg. increase of $20 \%$ in CHT co-efficient can be obtained by using $\mathrm{SiO}_{2} \mathrm{NPs}$ in smooth horizontal tubes in fully Turbulent regime. The temperature gradient between the fluid and wall will decrease significantly which significantly improves the heat transfer between the liquid and the wall. Possible reasons for enhancement in HT can also be increased thermal conductivity of NF and chaotic movement of NPs in the fluid. In the case of $0.15 \% \mathrm{SiO}_{2} \mathrm{NPs}$ higher value of CHT is detected due to NF's ability to obtain more HT compared to base fluid. The CHT also increases due to increase of Re number. The estimated value of Re is $7500-$ 21000. Almost 29\% increase in CHT was detected compared to base fluid at Re of 20,600 for $0.15 \% \mathrm{SiO} 2 \mathrm{NPs}$. In case of $0.05 \% \mathrm{SiO} 2 \mathrm{NPs}$ highest enhancement detected was 9-11\%.

\subsection{Effect of axial distance on Heat transfer}

Effect of axial distance on CHT rate is shown in figure 6.10. Heat transfer rate on eight axial positions along a $1 \mathrm{~m}$ tube was observed and represented graphically. At constant Re decrease in HT co-efficient was observed and at the end almost constant trend was observed. It has been resulted that increase in distance decrease the CHT co-efficient. The axial distance effect on CHT in all three concentrations of $\mathrm{SiO} 2$ based water-EG NF is shown. The smallest change in the Re number is due to the change in viscosity and the density of Nano fluid because of change in Conc. of NPs compared to base fluid.

Increased CHT also occurs axially with increased particle concentration. But overall, decline in the trend of CHT coefficient is estimated. Gradual decrease in CHT was observed moving away from the test section but at $\mathrm{x}=0.575$ where $\mathrm{x} / \mathrm{D}=35$, approximately a statistically inclined trend was observed. A significant increase in the HT is detected compared to base fluid with the use of suspended NPs. Experimental results conclude that important parameter for the improved heat transfer rate is particle volume fraction. While volume concentration of NPs during this experimentation increased from 0.05 to $0.15 \%$.

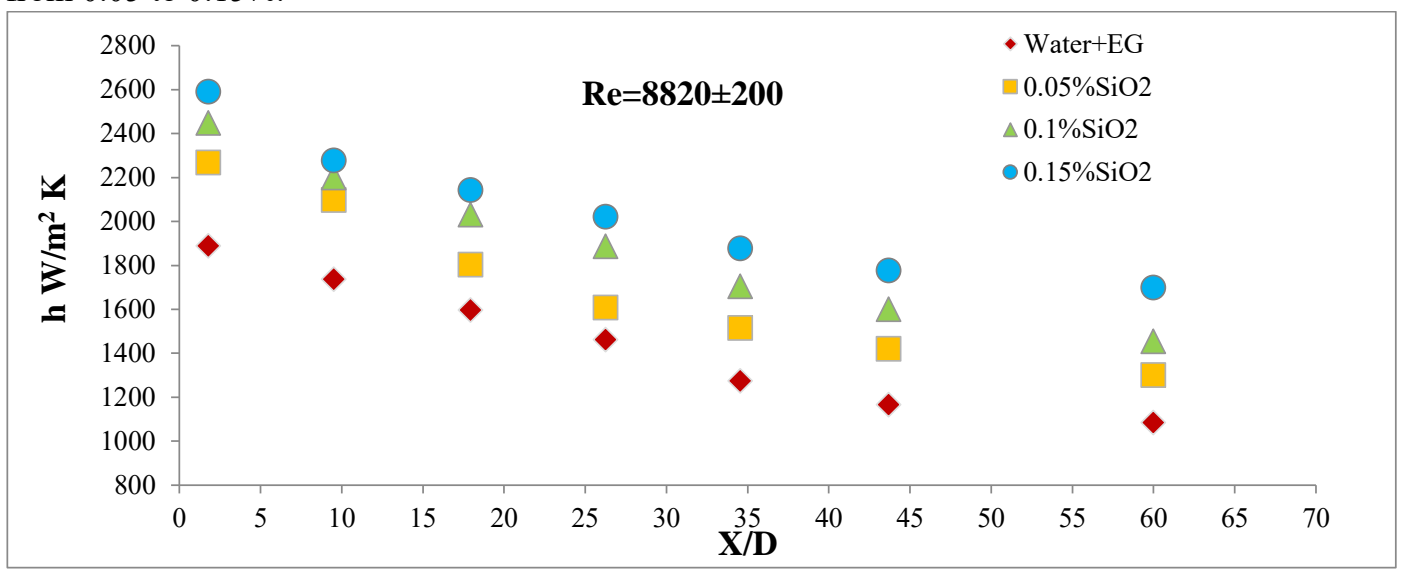

Figure 6. Axial distance vs heat transfer coefficient at $150 \mathrm{~W}$ 


\subsection{Wall Temperature}

The wall temperature of copper tube reduced in systematic way with increase in Re. As the Re increases wall temperature decreases because of increase in flow rate. Water shows highest wall temperature when compared with other NFs. When concentration of NFs increases, the decrease in wall temperature observed. In case of constant heat flux, $T_{w}-T_{f}$ is observed when distance change axially. Constant trend is observed in the fully developed regime. This is because when fluid flows axially along the tube $T_{f}$ also increase linearly and same is with the wall temperature. Since $\mathrm{T}_{\mathrm{w}}-\mathrm{T}_{\mathrm{f}}$ remains constant.

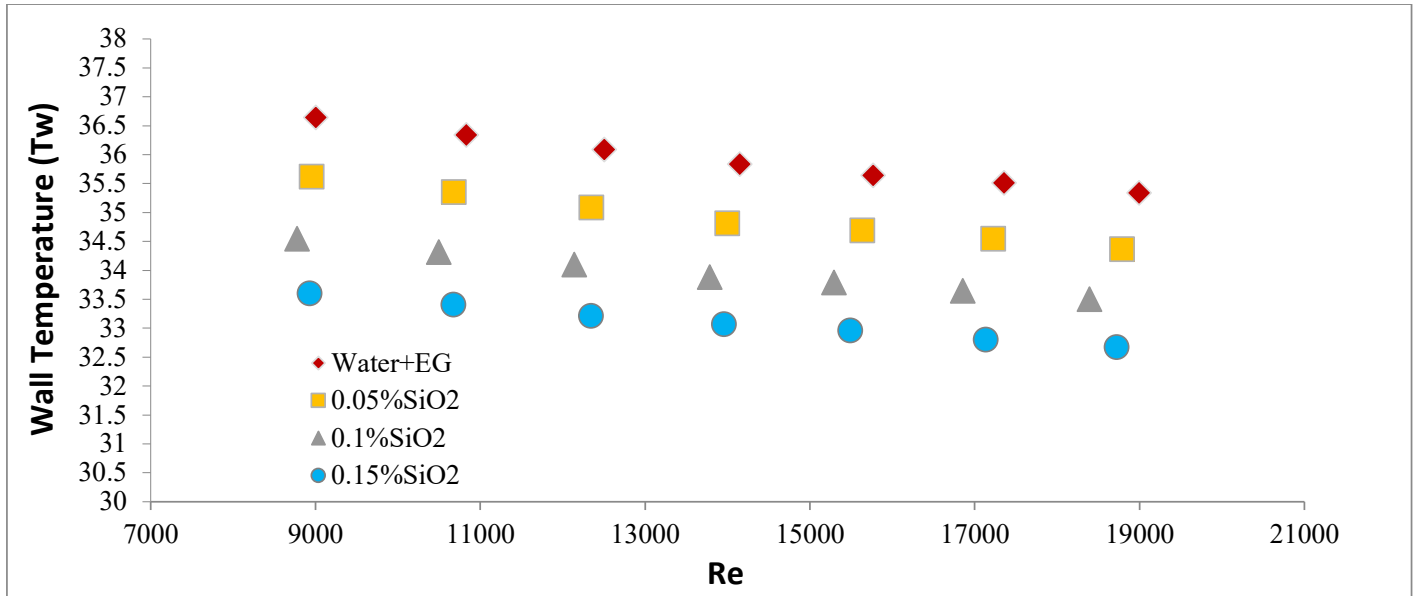

Figure 7. Variation in wall temperature against Reynolds number at 150W

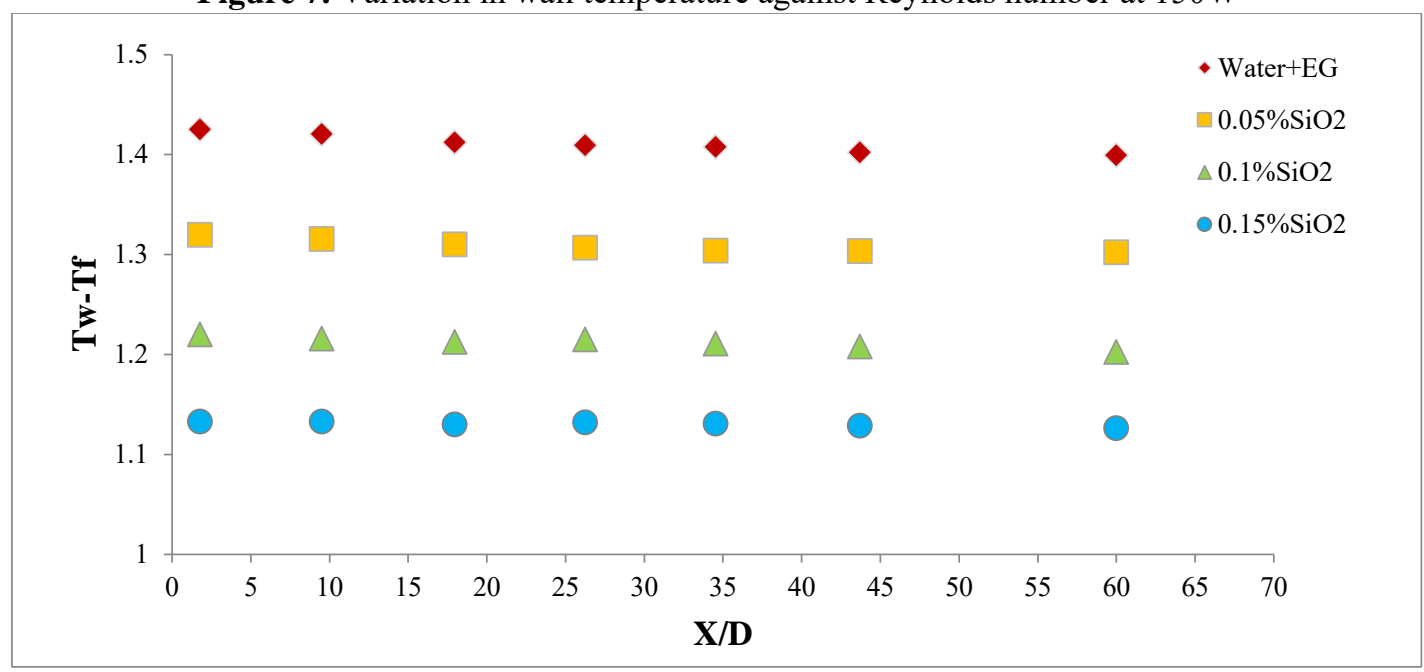

Figure 8. Variation in Tw-Tf by changing axial distance axially at $150 \mathrm{~W}$

Decreasing trend of wall temperature was detected due to increase in Re. The lowest wall temperature was observed at $0.15 \% \mathrm{SiO}_{2}$ /water-EG Nano fluid, because at higher concentration NFs absorbs more heat. A const. trend in $\mathrm{T}_{\mathrm{w}}-\mathrm{T}_{\mathrm{f}}$ is seen because axially in the case of const. heat flux, constant value of CHT is observed.

\section{Conclusion:}

Experimental investigation has been conducted to test the internal CHT of Nanofluid in a copper tube in fully turbulent regime. Using all three concentrations of $\mathrm{SiO}_{2} 0.05,0.1$ and $0.15 \%$, significant improvement is observed for $\mathrm{SiO}_{2}$ based Water-EG Nano-fluid. At different points along the tube, Local CHT is observed. Depending on the coefficient heat transfer in conjunction with Re number variability, particle volume concentration and axial distance are observed. From all these calculations, we concluded that: 
1. Approximately $29 \%$ enhancement in coefficient of heat transfer is seen at maximum Re of 19,200 compared to water-EG at $0.15 \% \mathrm{SiO}_{2}$ NPs. At $0.1 \quad \mathrm{SiO}_{2} \mathrm{NPS}$, the significant enhancement considered is $9-11 \%$. Enhancement in CHT is also seen with increase in concentrations of NPs.

2. Local CHT at two distinct points along the tube is detected with varying Re and axial distance. A significant increment in heat transfer is observed at entry point $\mathrm{P} 1(\mathrm{x}=0.0254)$ of test section, while $21 \%$ enhancement in CHT co-efficient is observed at $0.15 \%$ vol. concentration of $\mathrm{SiO} 2$ NPs. With increase of Re number, an increase in CHT is observed. However, a decrease in trend was observed with changing distance axially along the tube.

3. From all of these results, we conclude that the possible reason for the enhancement of the CHT is not only the increase in the TC of the NFs but also migration of particle, disruptive movement of the NPs and fluid fluctuations are. All of these factors cause turbulence and lowering the thermal boundary layer which increases rate of heat transfer compared to base fluid.

\section{Acknowledgment:}

The facilities provided by laboratory and financial support by University of engineering and technology Taxila, Pakistan are highly acknowledged.

\section{References:}

[1] R. Mohebbi, M.M. Rashidi, M. Izadi, N.A.C. Sidik, H.W. Xian, Forced convection of nanofluids in an extended surfaces channel using lattice Boltzmann method, Int. J. Heat Mass Transf. 117 (2018) 1291-1303.

[2] Y. Ma, R. Mohebbi, M.M. Rashidi, Z. Yang, Study of nanofluid forced convection heat transfer in a bent channel by means of lattice Boltzmann method, Phys. Fluids. 30 (2018) 32001.

[3] Y. Vermahmoudi, S.M. Peyghambarzadeh, S.H. Hashemabadi, M. Naraki, Experimental inv[estigation on heat transfer performance of Fe2O3/water nanofluid in an air-finned heat exchanger, Eur. J. Mech. B/Fluids. 44 (2014) 32-41. doi:10.1016/j.euromechflu.2013.10.002.

[4] M. Jafari, M. Farhadi, K. Sedighi, Convection heat transfer of SWCNT-nanofluid in a corrugated channel under pulsating velocity profile, Int. Commun. Heat Mass Transf. 67 (2015) 137-146.

[5] C.G. Granqvist, R.A. Buhrman, J. Wyns, A.J. Sievers, Far-infrared absorption in ultrafine Al particles, Phys. Rev. Lett. 37 (1976) 625.

[6] S.U.S. Choi, D.A. Singer, H.P. Wang, Developments and applications of non-Newtonian flows, Asme Fed. 66 (1995) 99-105.

[7] J.C. Maxwell, A treatise on electricity and magnetism, Oxford: Clarendon Press, 1873.

[8] S.U.S. Choi, Z.G. Zhang, W. Yu, F.E. Lockwood, E.A. Grulke, Anomalous thermal conductivity enhancement in nanotube suspensions, Appl. Phys. Lett. 79 (2001) 2252-2254. doi:10.1063/1.1408272.

[9] M.M. Ali, M.A. Alim, S.S. Ahmed, Numerical Simulation of Hydromagnetic Natural Convection Flow in a Grooved Enclosure Filled with $\mathrm{CuO}$-Water Nanofluid Considering Brownian Motion, Int. J. Appl. Comput. Math. 4 (2018) 1-24. doi:10.1007/s40819-018-0563-1.

[10] N.T. Ravi Kumar, P. Bhramara, B.M. Addis, L.S. Sundar, M.K. Singh, A.C.M. Sousa, Heat transfer, friction factor and effectiveness analysis of Fe3O4/water nanofluid flow in a double pipe heat exchanger with return bend, Int. Commun. Heat Mass Transf. 81 (2017) 155-163. doi:10.1016/j.icheatmasstransfer.2016.12.019.

[11] U. Khan, N. Ahmed, S.T. Mohyud-Din, Analysis of magnetohydrodynamic flow and heat transfer of Cu-water nanofluid between parallel plates for different shapes of nanoparticles, Neural Comput. Appl. 29 (2018) 695703. doi:10.1007/s00521-016-2596-x.

[12] J.H. Lee, K.S. Hwang, S.P. Jang, B.H. Lee, J.H. Kim, S.U.S. Choi, C.J. Choi, Effective viscosities and thermal conductivities of aqueous nanofluids containing low volume concentrations of Al2O3 nanoparticles, Int. J. Heat Mass Transf. 51 (2008) 2651-2656. doi:10.1016/j.ijheatmasstransfer.2007.10.026.

[13] Y. Hwang, J.K. Lee, C.H. Lee, Y.M. Jung, S.I. Cheong, C.G. Lee, B.C. Ku, S.P. Jang, Stability and thermal conductivity characteristics of nanofluids, Thermochim. Acta. 455 (2007) 70-74. doi:10.1016/j.tca.2006.11.036.

[14] J.A. Eastman, S.U.S. Choi, S. Li, W. Yu, L.J. Thompson, Anomalously increased effective thermal conductivities of ethylene glycol-based nanofluids containing copper nanoparticles, Appl. Phys. Lett. 78 (2001) 718-720. doi:10.1063/1.1341218.

[15] H.M. Ali, M.U. Sajid, A. Arshad, Heat transfer applications of TiO2 nanofluids, Appl. Titan. Dioxide. (2017).

[16] S.M. Peyghambarzadeh, S.H. Hashemabadi, S.M. Hoseini, M. Seifi Jamnani, Experimental study of heat transfer enhancement using water/ethylene glycol based nanofluids as a new coolant for car radiators, Int. Commun. Heat Mass Transf. 38 (2011) 1283-1290. doi:10.1016/j.icheatmasstransfer.2011.07.001.

[17] H.M. Ali, H. Ali, H. Liaquat, H.T. Bin Maqsood, M.A. Nadir, Experimental investigation of convective heat 
transfer augmentation for car radiator using ZnO-water nanofluids, Energy. 84 (2015) 317-324. doi:10.1016/j.energy.2015.02.103.

[18] K.Y. Leong, R. Saidur, S.N. Kazi, A.H. Mamun, Performance investigation of an automotive car radiator operated with nanofluid-based coolants (nanofluid as a coolant in a radiator), Appl. Therm. Eng. 30 (2010) 2685-2692. doi:10.1016/j.applthermaleng.2010.07.019.

[19] M.S. Wadd, D.R.M. Warkhedkar, V.G. Choudhari, Comparing performance of nanofluids of metal and nonmetal as coolant in automobile radiator, Int. J. Adv. Res. Sci. Eng. IJARSE. 4 (2015) 182-190.

[20] M. Kole, T.K. Dey, Investigation of thermal conductivity, viscosity, and electrical conductivity of graphene based nanofluids, J. Appl. Phys. 113 (2013). doi:10.1063/1.4793581.

[21] I. Zakaria, W.H. Azmi, W.A.N.W. Mohamed, R. Mamat, G. Najafi, Experimental Investigation of Thermal Conductivity and Electrical Conductivity of Al2O3 Nanofluid in Water - Ethylene Glycol Mixture for Proton Exchange Membrane Fuel Cell Application, Int. Commun. Heat Mass Transf. 61 (2015) 61-68. doi:10.1016/j.icheatmasstransfer.2014.12.015.

[22] L.S. Sundar, M.H. Farooky, S.N. Sarada, M.K. Singh, Experimental thermal conductivity of ethylene glycol and water mixture based low volume concentration of Al2O3 and $\mathrm{CuO}$ nanofluids, Int. Commun. Heat Mass Transf. 41 (2013) 41-46. doi:10.1016/j.icheatmasstransfer.2012.11.004.

[23] M.C.S. Reddy, V.V. Rao, Experimental studies on thermal conductivity of blends of ethylene glycol-waterbased TiO2 nanofluids, Int. Commun. Heat Mass Transf. 46 (2013) 31-36. doi:10.1016/j.icheatmasstransfer.2013.05.009.

[24] S. Osman, M. Sharifpur, J.P. Meyer, Experimental investigation of convection heat transfer in the transition flow regime of aluminium oxide-water nanofluids in a rectangular channel, Int. J. Heat Mass Transf. 133 (2019) 895-902. doi:10.1016/j.ijheatmasstransfer.2018.12.169.

[25] P. Taylor, C.C. Wang, P.Y. Chen, J.Y. Jang, Experimental Heat Transfer: A Journal of Thermal Energy Generation, Transport, Storage, and Conversion CONVEX-LOUVER FIN-AND-TUBE HEAT EXCHANGERS, (2007) 37-41. doi:10.1080/08916159208946431.

[26] D. Wen, Y. Ding, Experimental investigation into convective heat transfer of nanofluids at the entrance region under laminar flow conditions, Int. J. Heat Mass Transf. 47 (2004) 5181-5188. doi:10.1016/j.ijheatmasstransfer.2004.07.012.

[27] T.H. Nassan, S.Z. Heris, S.H. Noie, A comparison of experimental heat transfer characteristics for Al 2 O 3 /water and CuO/water nanofluids in square cross-section duct, Int. Commun. Heat Mass Transf. 37 (2010) 924-928. doi:10.1016/j.icheatmasstransfer.2010.04.009.

[28] C.T. Nguyen, G. Roy, C. Gauthier, N. Galanis, Heat transfer enhancement using Al2O3-water nanofluid for an electronic liquid cooling system, Appl. Therm. Eng. 27 (2007) 1501-1506. doi:10.1016/j.applthermaleng.2006.09.028.

[29] A.İ. Özdemir, R. Düzgün, Türkiye'deki Otomotiv Firmalarinin Sermaye Yapisina Göre Etkinlik Analizi, Atatürk Üniversitesi İktisadi ve İdari Bilim. Derg. 23 (2009) 147-164. 